\title{
Screening Rice (Oryza sativa. L.) for Salinity Tolerance for Yield and Yield Components in Saline Stressed Environment
}

\author{
Andrew Abiodun Efisue*, Cynthia Chimezie Dike \\ Development of Crop \& Soil Science, University of Port Harcourt, Port Harcourt, Nigeria
}

Email address:

andyefisue@yahoo.com (A. A. Efisue)

${ }^{*}$ Corresponding author

\section{To cite this article:}

Andrew Abiodun Efisue, Cynthia Chimezie Dike. Screening Rice (Oryza sativa. L.) for Salinity Tolerance for Yield and Yield Components in Saline Stressed Environment. American Journal of Agriculture and Forestry. Vol. 8, No. 1, 2020, pp. 15-21. doi: 10.11648/j.ajaf.20200801.13

Received: January 12, 2020; Accepted: January 27; Published: February 10, 2020

\begin{abstract}
Rice is one of the most important staple crops consumed by a large part of the human population but the issue of salinity is one of the limiting factors affecting its productivity. The objective of this study was to identify salt tolerant genotype for deployment into salt stressed regions and also for population improvement for salinity breeding programme. Material and Methods: the study was a potted experiment using 8 korean lines and UPIA1 and UPIA2 as check in a randomized complete block design with four levels of sodium chloride concentration $(0,2,3$ and $6 \mathrm{dS} / \mathrm{m})$ replicated three times at the University of Port Harcourt Teaching and Research Farm. Result: most of the genotype showed differential response to salinity stress. Varieties like UPN 509, UPN 216, constantly showed high mean value for Leaf Area Index, 1000 grain weight, plant height and tillering ability across the salinity concentration gradient in salinity tolerance index. Principle Component 1 and 2 contributed $46.17 \%$ and $15.17 \%$ respectively of the total variation. Total grain yield showed strong positive significant correlation with plant height, grain weight per panicle leaf area index and 1000 grain weight. In conclusion, UPN 509 which showed the highest yielding capacity and UPN 216 which showed the highest tillering ability and tolerance to salinity stress at the highest concentration level maybe promising genotypes for deployment into saline stressed environment.
\end{abstract}

Keywords: Oryza Sativa, Salinity, Yield, Yield Components, Salinity Tolerance Index

\section{Introduction}

Rice (Oryza sativa) (Asian rice) and Oryza glaberrima (African rice) are two dominants and most cultivated among the oryza species. Rice is a staple crop and now becoming as income generation for rice farmers all over the world and is one of the most important cereal and widely consumed as staple food for a large world population. As the world population is on the increase, thus leading to high demand in rice consumption all over the world. This become a challenge for sustainability and sufficient rice production to meet the consumption rate [1] One of the most assured ways of sustainability is to breed durable and resilient rice varieties with high yield and good agronomic traits preferred by rice stakeholders. Salinity is one of the major abiotic stresses that affect rice productivity. Rice is very sensitive to salinity stress and listed as the most salt sensitive cereal [2] and several studies have shown that rice is tolerant during germination, but becomes very sensitive during early seedling. It again becomes more tolerant during vegetative growth with the sensitivity returning again during pollination and fertilization and finally it again becomes more tolerant at maturity [3]. Salinity (excess amount of soluble salts in the soil solution) is a major stress limiting the production of food crops. Salinity induces water deficit even in well-watered soils by decreasing the osmotic potential of soil solutes thus making it difficult for roots to extract water from their surrounding media [4].

Salts affect plant growth due to increasing soil osmotic pressure thus interferes with plant nutrition. A high salt concentration in soil solution reduces the ability of plants to acquire water, which is referred to as the osmotic or waterdeficit effect of salinity. Damage occurs when the concentration is high enough to begin reducing crop growth. 
Two-phase model was proposed to depict the response of plant growth to salinity [5]. The first phase is very rapid and growth reduction is ascribed to development of a water deficit. The second phase is due to the accumulation of salts in the shoot at toxic levels and is very slow. Salinity affects photosynthesis by decreasing $\mathrm{CO}_{2}$ availability as a result of diffusion limitations [6] and a reduction of the contents of photosynthetic pigments [7]

Salinity also affect yield related traits thus reduced the yield potential of the rice variety. Tillering in rice is an important agronomic trait for grain production. In rice, the manipulation of tiller number is important for grain yield. High number of tiller result in higher sink-source ratio, spikelet number, proportion of filled grain [8]. The number of tillers per plant is an important parameter under salinity because it determines the grain bearing panicles and that increasing salinity decreases number of tillers and plant height determines lodging behavior hence determine yield [9]. Plant height is measured from the soil surface to the tip of the tallest leaf and increasing salinity reduces plant height of rice [10]. With increased photosynthetic activity, yield tends to increase. It has been reported in previous studies [11] that increase in salinity decreases leaf area hence lead to a decrease in the total number of leaves which can affect yield of rice. Selection of plant with high leave area is a criterion for increasing grain yield in rice and rice lines with high leave area value could produce better yield than lines with low leaf area [12]

Despite the advanced management technologies available today, salinization of millions of hectares of land continues to reduce crop production severely world-wide. The threat of this has led to the concept of screening for varieties that are resistant to salinity. The development of rice cultivars which have potential for salt tolerance is an important aim in the breeding programs [13]. As well, improving rice productivity through identification of the best performing genotypes and genotypes that can be used as parents in future crosses are two principal objectives of most rice breeding programs [14]. This study was therefore, conducted to determine salinity tolerance rice for yield and yield related traits for salinity stressed environments.

\section{Materials and Method}

\subsection{Location of Study Area}

The experimental study was located at the University of Port Harcourt, Faculty of Agriculture Teaching and Research Farm Choba, River State. Geographically, River State is located in the Southern part of Niger Delta of Nigeria. Its temperature ranges from $21.8^{\circ} \mathrm{C}$ to $33.5^{\circ} \mathrm{C}$, it lies on latitude $4^{\circ} 31$ to $5^{\circ} 00 \mathrm{~N}$ and longitude $6^{\circ} 45$ to $7^{\circ} 00 \mathrm{E}$, with an average annual rainfall that ranges from $2500 \mathrm{~mm}$ to $4000 \mathrm{~mm}$ with an elevation of 20 metre above sea level.

\subsection{Genetic Materials Used for the Study}

Ten rice genotypes were used comprised eight Korean anther culture derived lines and two improved adapted Nigeria rice varieties. (Table 1). The experiment was a potted experiment using a Randomized Complete Block Design (RCBD) replicated 3 times using 4 levels of treatment. The experiment is a $10 \times 4$ factorial where factor $\mathrm{A}$ is the 10 -rice variety used for the experiment and factor B is the 4 level of sodium chloride applied. Soil preparation was done by sterilizing the soil. Sterilization was done by heating the soil collected for planting for 6 hours to kill weed seeds, nematode and other parasitic organisms. After sterilization, each pot was filled with $10 \mathrm{~kg}$ soil. Planting was carried out by dibbling 3 seeds per pot and irrigation was done as at when due at soil field capacity. Inorganic fertilizer (NPK $15: 15: 15)$ was applied in a basal application of $200 \mathrm{~kg} \mathrm{ha}^{-1}$ $\left(\mathrm{N}_{2}, \mathrm{P}_{2} \mathrm{O}_{5}\right.$ and $\left.\mathrm{K}_{2} \mathrm{O}\right)$. Thinning was done two weeks after planting. Seedling was thinned to two seedlings per pot. Weeding was done manually by hand as at when due.

Treatment applied involved four levels of sodium chloride concentration which include $0,2,3$, and $6 \mathrm{dS} / \mathrm{m}$. The salt concentration was chosen based on the already established salinity threshold for rice [2]. Salinity was induced by weighing out $1236 \mathrm{mg}$ of salt and diluting it in 1 liter of water to get $2 \mathrm{dS} / \mathrm{m}$ concentration level. $3 \mathrm{dS} / \mathrm{m}$ concentration level was achieved by weighing out $1688 \mathrm{mg}$ of salt and diluting it in 1 liter of water to get $3 \mathrm{dS} / \mathrm{m}$ concentration level. $6 \mathrm{dS} / \mathrm{m}$ concentration level was achieved by weighing out $3375 \mathrm{mg}$ of salt and diluting it in 1 liter of water to get $6 \mathrm{dS} / \mathrm{m}$ concentration level. The Electrical conductivity meter by HANNA instruments model HI 9835 was used to calibrate the salinity level of the salt solution.

Table 1. Below shows the list of genetic material used for the experiment.

\begin{tabular}{lll}
\hline S/N & VARIETY & SOURCE \\
\hline 1 & UPN 509 & AGRA Germplasm Uniport \\
2 & UPN440 & AGRA Germplasm Uniport \\
3 & UPN216 & AGRA Germplasm Uniport \\
4 & UPN 528 & AGRA Germplasm Uniport \\
5 & UPN 337 & AGRA Germplasm Uniport \\
6 & UPN 177 & AGRA Germplasm Uniport \\
7 & UPN 565 & AGRA Germplasm Uniport \\
8 & UPN 407 & AGRA Germplasm Uniport \\
9 & UPIA1 & AGRA Germplasm Uniport \\
10 & UPIA2 & AGRA Germplasm Uniport \\
\hline
\end{tabular}

\subsection{Data Collection}

Data was collected at the appropriate stage of the crop development. The Standard Evaluation System (SES) for rice reference manual [15] was used for all trait measurement except where stated otherwise. The following data was taken at the appropriate plant phenology; Plant Height was measured in $\mathrm{cm}$ using meter rule from the plant base to the tip of the highest leaf and leaf area (LA) was determined using a leaf area meter (li-3100, Lincoln, NE USA). Area Index (LAI) was calculated as described [16] as follows. LAI $=$ (sum of the Leaf Area of all leaves per unit area where the leaves have been collected. Effective Tillers of each plant were counted to determine the total number of panicles in each plant and Panicle Length was measured using a meter 
rule. Grain Weight per Panicle was measured after threshing the representative panicle and weighed using a weighing balance. 1000 Grain Weight was measured by counting out 1000 grain from the total yield of each variety and weighing it using a weighing balance and total Grain Yield was measured by weighing all the grain harvested from each variety

\subsection{Statistical Analysis}

All data collected was subjected to Analysis of Variance using PROC GLM of SAS [17] and means where separated using Duncan Multiple Testing at 5\%. Correlation Analysis was done using PROC CORR of SAS to determine the relationship and association among the agronomic trait.

Salinity Tolerance Index was calculated as sited [10] to determine which variety is more tolerant to salinity stress.

$$
\mathrm{STI}=\frac{Y s \times Y p}{Y p 2}
$$

Where STI = Salinity Tolerance Index, Ys and Yp are mean values of the agronomic trait of genotypes/varieties under saline (stressed) and non-saline condition respectively. While $\mathrm{Yp}^{2}$ overall mean of all genotype/varieties evaluated under non-saline condition. Principle Component Analysis done using PRINCOM of SAS

\section{Results}

\subsection{Performance of Yield Related Traits}

Plant Height had significance variation among the 10 genotypes used for the experiment tested at $(\mathrm{P} \leq 0.001)$. About 6 genotypes performed better than the over-all mean value for plant height $(87.63111 \mathrm{~cm})$. Average value for plant height for the varieties used for the experiment ranges from
$(66 \mathrm{~cm}-96 \mathrm{~cm})$ with UPN509 having the highest plant height of 95.86 and UPIA 2 having the lowest plant height of $66.633 \mathrm{~cm}$. Among the genotypes, there are significant difference between the means of the plant height. UPN509 was significantly different from UPIA 2 in their mean height. In general, plant height showed a very high significant difference among the genotypes tested at $(\mathrm{P} \leq 0.001)$ (Table 2). The Leaf Area Index (LAI), about 5 genotypes had their average mean values above the grand mean of 1.24. Leaf Area Index for genotypes used for the experiment ranged from 0.3-1.7 with UPN177 having the highest leaf area index and UPIA2 having the lowest leaf area index. Among the genotypes, UPN509, UPN177, 440 was significantly different fromUPN565 and UPIA2. In general, Leaf Area Index show a very high significant difference in leaf area index among the genotypes tested at $(\mathrm{P} \leq 0.001)$. The 1000 Grain Weight, 5 varieties such as UPN509 had their mean value above the grand mean value of 16.87. Mean value for genotypes used for the experiment ranged from 9.61g $21.11 \mathrm{~g}$ with UPN 509 having the highest mean value of 21.1g followed by UPN 528 and UPN 440 having an average weight of $19.556 \mathrm{~g}$ and $19.500 \mathrm{~g}$ respectively. Among the genotypes, UPN 509 was significantly different from UPN 565 and UPIA2. The Grain Weight per Panicle, 5 genotypes such as UPN 509, UPN 407 and UPN 528, had their mean values for grain weight per panicle greater than the overall. Grain weight per panicle for genotypes used for the experiment ranged from $0.69 \mathrm{~g}-1.43 \mathrm{~g}$ with UPN 528 having the highest mean value of $1.43 \mathrm{~g}$ and UPN 337 having the lowest mean value of $0.68 \mathrm{~g}$. In general, grain weight per panicle showed significant difference among the lines tested at 0.05 , while Panicle Length, showed significance difference $(\mathrm{P} \leq 0.001)$ among the genotypes Table 2 .

Table 2. Agronomic Performance of Genotypes Used for the Experiment.

\begin{tabular}{|c|c|c|c|c|c|c|c|}
\hline GENOTYPES & PH & LAI & $1000 \mathrm{GW}$ & TGY & PANWT & GWTP & PANLT \\
\hline UPN407 & $93.43^{\mathrm{ab}}$ & $1.09^{\mathrm{ab}}$ & $16.48^{\mathrm{ab}}$ & $3.62^{\mathrm{abc}}$ & $1.34^{\mathrm{abc}}$ & $1.18^{\mathrm{abc}}$ & $16.52^{\mathrm{b}}$ \\
\hline UPN509 & $95.86^{\mathrm{a}}$ & $1.64^{\mathrm{a}}$ & $21.11^{\mathrm{a}}$ & $5.53^{\mathrm{a}}$ & $1.43^{\mathrm{ab}}$ & $1.31^{\mathrm{ab}}$ & $17.81^{\mathrm{b}}$ \\
\hline UPN177 & $89.24^{\mathrm{ab}}$ & $1.70^{\mathrm{a}}$ & $18.88^{\mathrm{ab}}$ & $3.92^{\mathrm{abc}}$ & $0.92^{\mathrm{bc}}$ & $0.83^{\mathrm{bc}}$ & $18.17^{\mathrm{b}}$ \\
\hline UPN565 & $82.38^{\mathrm{ab}}$ & $0.72^{\mathrm{bc}}$ & $14.37^{\mathrm{bc}}$ & $2.26^{\mathrm{c}}$ & $1.11^{\mathrm{abc}}$ & $0.93^{\mathrm{abc}}$ & $18.40^{\mathrm{b}}$ \\
\hline UPN216 & $85.70^{\mathrm{ab}}$ & $1.63^{\mathrm{a}}$ & $18.13^{\mathrm{ab}}$ & $4.58^{\mathrm{abc}}$ & $1.21^{\mathrm{abc}}$ & $1.07^{\mathrm{abc}}$ & $17.40^{\mathrm{b}}$ \\
\hline UPN528 & $93.82^{\mathrm{ab}}$ & $1.39^{\mathrm{ab}}$ & $19.56^{\mathrm{ab}}$ & $4.41^{\mathrm{abc}}$ & $1.62^{\mathrm{a}}$ & $1.43^{\mathrm{a}}$ & $19.08^{\mathrm{b}}$ \\
\hline UPA2 & $66.63^{b}$ & $0.30^{\mathrm{c}}$ & $9.61^{\mathrm{c}}$ & $2.00^{\mathrm{c}}$ & $1.06^{\mathrm{abc}}$ & $0.73^{\mathrm{c}}$ & $22.32^{\mathrm{a}}$ \\
\hline UPA1 & $88.30^{\mathrm{ab}}$ & $1.20^{\mathrm{ab}}$ & $14.33^{\mathrm{bc}}$ & $3.07^{\mathrm{abc}}$ & $1.39^{\mathrm{abc}}$ & $1.22^{\mathrm{abc}}$ & $23.62^{\mathrm{a}}$ \\
\hline Mean & 87.63 & 1.24 & 16.87 & 3.68 & 1.24 & 1.07 & 18.74 \\
\hline $\mathrm{CV} \%$ & 13.24 & 52.28 & 30.63 & 67.89 & 43.28 & 46.17 & 15.23 \\
\hline LSD & 10.89 & 0.61 & 4.85 & 2.35 & 0.51 & 0.47 & 2.68 \\
\hline P. Value & $* * *$ & $* * *$ & $* *$ & ns & ns & * & $* * *$ \\
\hline
\end{tabular}

$* * *$ and $* * *$ significant at $0.05,0.01$, and 0.001 probability level while $\mathrm{ns}=$ non significant. PH=plant height, LAI $=$ leaf Area Index, $1000 \mathrm{GW}=1000 \mathrm{grain}$ Weight, TGY $=$ Total Grain Weight, PANWT $=$ Panicle Weight, GWTP $=$ Grain Weight per Panicle, PANLT $=$ Panicle Length, P. Value $=$ Probability value

\subsection{Effect of Salinity on Plant Height}

In Table 3, UPN 337 had the highest mean value in EC0, In EC2 UPN 528 had the highest mean value and EC3, UPN 509 had the highest mean value for plant height across concentration level, UPN 528 and UPN 216 had their mean value greater inEC2 and EC3 than EC0. Genotypes such as UPIA2 and UPN 337 showed the highest degree of salinity effects with the mean value for plant height at EC0 significantly different from EC3. In general, most of the 
varieties had their height decrease at EC3 compared to EC0. The EC2 showed significant difference among the genotypes. This implies that treatment has effect on the plant height at EC2 (Table 3).

Table 3. Effect of Salinity on Plant Height (Cm) Of Genotype Used for the Experiment across Concentration Gradient.

\begin{tabular}{llll}
\hline GENOTYPES & EC0 & EC2 & EC3 \\
\hline UPN 407 & $97.78^{\mathrm{a}}$ & $98.13^{\mathrm{a}}$ & $84.30^{\mathrm{abc}}$ \\
UPN 509 & $99.82^{\mathrm{a}}$ & $95.25^{\mathrm{a}}$ & $92.45^{\mathrm{a}}$ \\
UPN 177 & $90.30^{\mathrm{ab}}$ & $89.63^{\mathrm{a}}$ & $87.73^{\mathrm{ab}}$ \\
UPN 337 & $101.30^{\mathrm{a}}$ & $90.60^{\mathrm{a}}$ & $70.32^{\mathrm{bc}}$ \\
UPN 565 & $83.17^{\mathrm{ab}}$ & $82.20^{\mathrm{a}}$ & $81.77^{\mathrm{abc}}$ \\
UPN 216 & $88.58^{\mathrm{ab}}$ & $80.17^{\mathrm{a}}$ & $88.28^{\mathrm{ab}}$ \\
UPN 528 & $92.00^{\mathrm{ab}}$ & $100.45^{\mathrm{a}}$ & $88.93^{\mathrm{a}}$ \\
UPN 440 & $96.82^{\mathrm{a}}$ & $95.32^{\mathrm{a}}$ & $88.32^{\mathrm{a}}$ \\
UPA2 & $75.85^{\mathrm{b}}$ & $57.48^{\mathrm{b}}$ & $66.47^{\mathrm{c}}$ \\
UPA1 & $88.97^{\mathrm{ab}}$ & $99.98^{\mathrm{a}}$ & $75.88^{\mathrm{abc}}$ \\
Mean & $91.46^{\mathrm{a}}$ & $88.92^{\mathrm{a}}$ & 82.45 \\
CV\% & 11.07 & 11.94 & $12.72^{\mathrm{a}}$ \\
LSD & $17.37^{\mathrm{N}}$ & $18.22^{2}$ & 17.99 \\
P. value & $\mathrm{Ns}$ & $* * *$ & Ns \\
\hline
\end{tabular}

$\mathrm{EC}=$ Electrical Conductivity, $* * *$ significant at $0.001, \mathrm{P}$. value $=$ probability level while $\mathrm{ns}=$ non significant.

The effect of salinity on $1000 \mathrm{GWt}$ only the ECO showed significant difference at $(\mathrm{P} \leq 0.05)$ among the genotypes. Similarly, significant difference at $(\mathrm{P} \leq 0.05)$ was observed among the genotypes for panicle length at EC 2. Significant difference was not observed for tillering ability across the salinity concentration levels.

\subsection{Salinity Tolerance Index of the Studied Genotypes}

Genotypes such as UPN509, UPN 528, UPN 440, and UPN 216 had their mean values greater than the check (UPIA1 and UPIA2) with UPN 216 having the highest mean value at EC6 concentration level followed by UPN 509. The higher the STI value, the better the genotype performance under stressed condition. Therefore, for Leave Area Index (LAI), genotypes UPN 216 and UPN 509 performed better under this condition. There is wide range of STI value for LAI among the genotypes across the concentration levels (Table 4).

Table 4. Salinity Tolerance Index for Leave Area Index.

\begin{tabular}{llll}
\hline GENOTYPES & STI (EC2) & STI (EC3) & EC6 \\
\hline UPN 407 & 0.96 & 0.42 & 0.35 \\
UPN 509 & 1.65 & 1.37 & 0.46 \\
UPN 177 & 1.39 & 1.54 & 0.17 \\
UPN 337 & 0.81 & 0.82 & 0.12 \\
UPN 565 & 0.30 & 0.26 & 0.15 \\
UPN 216 & 1.78 & 1.45 & 0.47 \\
UPN 528 & 1.45 & 0.55 & 0.38 \\
UPN 440 & 1.58 & 1.16 & 0.22 \\
UPA2 & 0.05 & 0.06 & 0.01 \\
UPA1 & 1.04 & 0.57 & 0.399 \\
MEAN & 1.10 & 0.82 & 0.27 \\
STDEV & 0.58 & 0.53 & 0.16 \\
\hline
\end{tabular}

$\mathrm{STI}=$ Salinity tolerance index

In Table 5 UPN 216 had the highest mean value across the concentration gradient and at EC6 it was the only variety with mean value higher than the checks (UPIA1 and UPIA2). The higher the STI value, the better the genotype performance under stressed condition. There is wide range of STI value for tillering ability among the genotypes, thus, indicating high variability among the tested genotypes. This implies that UPN 216 had the highest tillering ability. In general, tillering ability reduced across concentration level. (Table 5)

Table 5. Salinity Tolerance Index for Tillering Ability.

\begin{tabular}{llll}
\hline GENOTYPES & STI (EC2) & STI (EC3) & STI (EC6) \\
\hline UPN407 & 0.78 & 0.44 & 0 \\
UPN509 & 1.45 & 1.02 & 0.17 \\
UPN177 & 2.76 & 2.20 & 0.28 \\
UPN337 & 0.577204 & 0.974057 & 0.144305 \\
UPN565 & 0.196913 & 0.157531 & 0.026255 \\
UPN216 & 2.834135 & 1.574834 & 1.102164 \\
UPN528 & 0.839544 & 0.236119 & 0 \\
UPN440 & 0.944712 & 0.472356 & 0 \\
UPIA2 & 0.118089 & 0.177133 & 0 \\
UPIA1 & 0.708534 & 0.944712 & 0.551082 \\
MEAN & 1.119218 & 0.820777 & 0.226995 \\
STDEV & 0.958882 & 0.668647 & 0.354296 \\
\hline
\end{tabular}

$\mathrm{STI}=$ Salinity tolerance index

In Table 6, generally, plant height decreases across concentration gradient. The mean value of the genotypes decreased across concentration gradient with UPN 407 having the highest mean value. The higher the STI value, the better the genotype performance under stressed condition, thus indicating high variability among the tested genotypes and UPN 407 the most performed genotype under this condition (Table 6).

Table 6. Stress Tolerance Index for Plant Height.

\begin{tabular}{llll}
\hline Genotype & STI (EC2) & STI (EC3) & STI (EC6) \\
\hline UPN 407 & 1.147181 & 0.985472 & 0.863311 \\
UPN 509 & 1.13664 & 1.103227 & 0.819017 \\
UPN 177 & 0.96763 & 0.947118 & 0.569461 \\
UPN 337 & 1.097213 & 0.851576 & 0.769826 \\
UPN 565 & 0.81729 & 0.812985 & 0.576843 \\
UPN 216 & 0.848984 & 0.934934 & 0.794794 \\
UPN 528 & 1.104819 & 0.978147 & 0.728297 \\
UPN 440 & 1.103254 & 1.022232 & 0.705085 \\
UPA2 & 0.521253 & 0.602719 & 0.283071 \\
UPA1 & 1.063429 & 0.807099 & 0.726091 \\
MEAN & 0.980769 & 0.904551 & 0.68358 \\
STDEV & 0.199497 & 0.141347 & 0.169819 \\
\hline
\end{tabular}

$\mathrm{STI}=$ Salinity tolerance index

\subsection{Correlation Analysis of the Studied Genotypes}

Total Grain Yield showed very strong significant positive correlation with Leaf Area Index, Grain Weight per Panicle, 1000 Grain Weight and plant height at probability level (0.001, 0.01, and 0.05), respectively. 1000 Grain Weight showed very strong positive significant correlation with leaf area index and plant height at $(\mathrm{P} \leq 0.001)$ level of significance. Panicle weight also showed very strong significant correlation with grain weight per panicle at $(\mathrm{P} \leq$ 
0.001) level of significance. Panicle length showed significant negative correlation with 1000 grain weight at $(\mathrm{P}$ $\leq 0.05)$ level of significance. Leaf area index and grain weight per panicle showed positive significant correlation with plant height at $(\mathrm{P} \leq 0.01)$ and $(\mathrm{P} \leq 0.05)$ level of significance, respectively (Table 7).

Table 7. Correlation Coefficient between Rice Yield and its Yield Component.

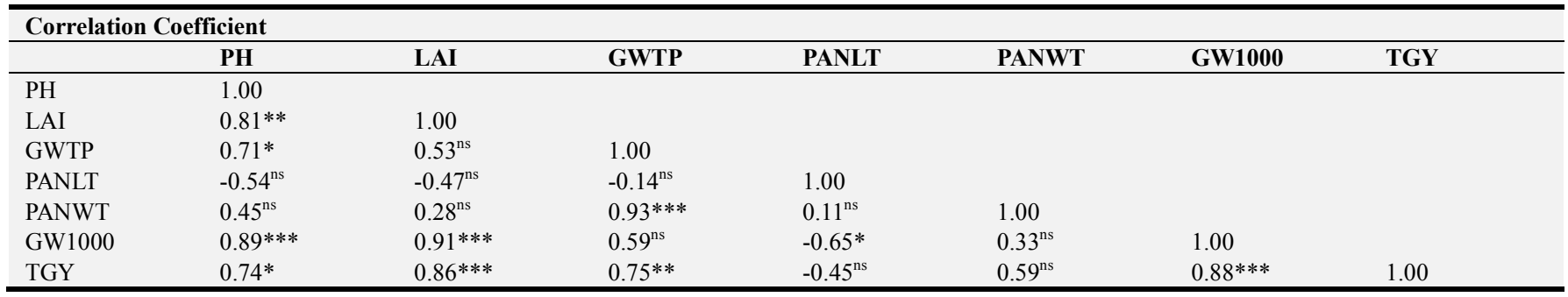

$*, * *$, and $* * *$ significant at $0.05,0.01$ and 0.001 probability level respectively, and $\mathrm{ns}=$ no significant observed

$\mathrm{PH}=$ plant height, LAI = leaf Area Index, 1000GW = 1000 grain Weight, TGY $=$ Total Grain Weight, PANWT $=$ Panicle Weight, GWTP $=$ Grain Weight per Panicle, PANLT $=$ Panicle Length

\subsection{Principal Component Analysis of the Studied Genotypes}

The Principle Component Analysis PCA 1 and PCA 2 contributed $46.97 \%$ and $15.17 \%$, respectively of the total variance observed in the experiment. The 1000 Grain weight, Total Grain Yield, plant height and leaf Area Index contributed most of the total variance in Prin 1 while panicle weight and panicle length contributed the highest for Prin 2. Panicle length had negative value in Prin 1 while plant height and leave area index had negative value in PCA 2. In PCA 3, LAI and PANLT contributed most, while PH, GW1000 and TGY contributed most for PCA 4, PCA 5 and PCA 6, respectively. (Table 8 ).

Table 8. Principal Component Analysis between Agronomic Traits.

\begin{tabular}{llllllll}
\hline \multicolumn{2}{l}{ Eigenvectors } & & & & & \\
\hline & Prin1 & Prin2 & Prin3 & Prin4 & Prin5 & Prin6 & Prin7 \\
\hline PH & 0.42 & -0.08 & -0.06 & 0.75 & 0.02 & 0.39 & 0.30 \\
LAI & 0.41 & -0.20 & 0.56 & -0.04 & -0.58 & -0.36 & 0.08 \\
GWTP & 0.38 & 0.44 & -0.23 & 0.10 & -0.24 & 0.04 & -0.74 \\
PANLT & -0.25 & 0.55 & 0.72 & 0.21 & 0.24 & 0.11 & -0.06 \\
PANWT & 0.28 & 0.63 & -0.26 & -0.13 & 0.04 & -0.37 & 0.55 \\
GW1000 & 0.43 & -0.23 & 0.12 & 0.02 & 0.73 & -0.41 & -0.21 \\
TGY & 0.43 & 0.03 & 0.18 & -0.60 & 0.13 & 0.63 & 0.10 \\
\hline
\end{tabular}

$\mathrm{PH}=$ plant height, LAI = leaf Area Index, 1000GW = 1000 grain Weight, TGY $=$ Total Grain Weight, PANWT $=$ Panicle Weight, GWTP $=$ Grain Weight per Panicle, PANLT $=$ Panicle Length, Prin 1, 2, 3, 4, 5, 6, $7=$ Principal Component 1, 2, 3, 4, 5, 6, 7 .

\section{Discussion}

\subsection{Agronomic Performance of Genotype}

Abiotic factors affecting crop production such as salinity, drought, cold and heat, have led to critical loss in crop yield.[18] The most important abiotic factor that has led critical loss in rice production is salinity and this could be as a result of human activities, industrialization, climate change etc. One of the objectives of rice breeders is to develop varieties with high salinity tolerance, high yielding capacity and other desirable agronomic traits. From the experiment, it was observed that the degree of salinity effect was higher in the $6 \mathrm{dS} / \mathrm{m}$ concentration level. This resulted to the decrease in yield and yield related traits which directly or indirectly affect yield such as plant height, leave area index, tillering ability, and this corroborated the reports $[10,19]$. Also, the $2 \mathrm{dS} / \mathrm{m} \mathrm{NaCl}$ concentration level was observed to perform better than better than all other concentration level including the control. This could be attributed to the presence of chloride ion $\left(\mathrm{Cl}^{-}\right)$produced when $\mathrm{NaCl}$ dissociate. Chloride ion $\left(\mathrm{Cl}^{-}\right)$is a micro-element which plays an important role in photosynthesis, suppress plant disease, enhance plant growth.[20]

Leave area index (LAI) is an important agronomic trait which tells the photosynthetic efficiency of a plant thus contributing to higher grain yield. Genotypes such as UPN 509, UPN528, UPN 177, and UPN 440 showed the highest mean value for leave area index had the highest mean value for total grain yield and this was in alignment with report.[12]. Plant Height is a predominant factor determine rice response to nitrogen. It determines the logging behavior, thus affect yield. Tall statue plant facilitates light penetration which may increase photosynthetic ability [20]. From the experiment, Genotypes such as UPN 509, UPN 528, UPN 440 showed the highest mean value across salinity concentration gradient and these varieties especially UPN 509 showed the highest mean value for total grain yield, this could be deployed to salinity prone environments.

Panicle length is one of the yield parameters that determine total yield. The length of the panicle determines the number of grains to be accommodated. Higher grain yield for varieties with longer panicle length have been reported $[21,22]$. Grain weight per panicle and panicle weight are important secondary traits for total grain yield. They are determined by the ability of the source (leaves) to supply assimilate to the sink during ripening and the sink (developing grain) to accumulate imported assimilate [23]. Cultivars with higher grain weight value size tend to have higher grain filling. From the experiment, genotypes such as UPN 509 UN 528, UPN 440 which showed the higher values for grain weight per panicle and panicle weight had higher grain yield, thus corroborate the earlier reports [24]. 


\subsection{Salinity Tolerance Index of Genotypes}

Stress tolerance index have been used by scientists to identify salt tolerant varieties across different across different ecologies at different stress levels [7]. The higher the salinity tolerance index value, the better the genotype performance under salinity stress. The use of physiological traits such as leaf area index, tillering ability, and plant height has been used by scientist to screen for salinity stress [11]. Genotypes such as UPN 509 and UPN 216 showed the highest mean value across concentration gradient for leave area index, Tillering, Plant height, and 1000 grain weight may be promising for salinity breeding program. Tillering ability is also an important agronomic trait for higher grain yield [25] found out that increased tillering leads to production of more panicles, which can lead to higher grain yield. From the experiment, genotypes such as UPN 509 and UPN 216, which showed the highest mean value for tillering ability and 1000 grain weight respectively may be promising for salinity breeding program.

\subsection{Correlation Analysis}

Total Grain Yield showed very strong significant positive correlation with Leaf Area Index, Grain Weight per Panicle, 1000 Grain Weight and plant height at probability levels (0.001, 0.01, and 0.05), respectively. The 1000 Grain Weight showed very strong positive significant correlation with leaf area index and plant height. Panicle weight also showed very strong significant correlation with grain weight per panicle. Leaf area index and grain weight per panicle showed positive significant correlation with plant height. This implies that increase in the aforementioned agronomic trait that showed high positive significant correlation resulted to an increase in agronomic trait they significantly and positively correlate to and this was in alignment with earlier work $[21,26]$. Panicle length showed significant negative correlation with 1000 grain weight. This implies that increase in panicle length caused a decrease in 1000 grain weight. Varieties such UPIA1 and UPIA2 that had the highest means value for panicle length had the lowest mean value for 1000 grain weight whereas varieties such as UPN 509, UPN 440 that had the lowest mean value for panicle length had the highest mean value for 1000 grain weight

\section{Conclusion}

Salinity stress affects the productivity of rice in saline environment. Screening and developing varieties with inherent salinity tolerance is one of the main objectives of rice plant breeders to enhance rice production. From the experiment varieties such as UPN509, UPN528, UPN440, UPN 216, and UPN177 may be promising for deployment into saline stressed environment because of their high leave area index, tillering ability, 1000 grain weight, total grain yield, grain weight per panicle which are major yield component. Also, their high weight and factor loading value as shown on the principal component analysis indicates that they are portative trait for salinity tolerance which could be used for population development in salinity breeding programme. However, UPN 509 which had the highest yielding capacity and UPN 216 which had the highest tillering ability and tolerance to salinity stress at the highest concentration level can be used to make crosses in breeding program. The morphological appearance presented by the plant in response to salinity stress may not be enough to determine its effect. Therefore, it is recommended that future studies should consider the physiological features of the following lines UPN 509, UPN 216 for further understanding.

\section{Acknowledgements}

Authors wish to express their gratitude to KAFAC of RDA Korea for providing the genetic materials (anther culture derived) used for this study.

\section{References}

[1] Kumar, A., Basu S., Venkategowda R., and Andy P. 2017. Mechanisms of drought tolerance in rice. Burleigh Dodds Science Publishing Limited: 131-63.

[2] United State Department of Agriculture, 2016. Research Databases, Bibliography on Salt Tolerance. George E. Brown, Jr. Ed.; Salinity Laboratory United State Department of Agriculture Research Service:, Riverside, CA, USA, Available at http://www.Ars.Usda.Gov/service/docs.Htm?Docid=8908 (Accessed on 19 October, 2019).

[3] Läuchli, A. and Grattan, S. R. 2007. Plant growth and development under salinity stress. In Advances in Molecular Breeding toward Drought and Salt Tolerant Crops; Springer: Dordrecht, the Netherlands, 2007; pp. 1-32.

[4] Sairam, R. K., Rao, K. V., Srivastava, G. C. 2002. Differential response of wheat genotypes to long-term salinity stress in relation to oxidative stress, antioxidant activity and osmolyte concentration. Journal of Plant Science, 163, pp. 1037-1046.

[5] Imolehin, E. D. and Wada, A. C., 2000. Meeting the rice production and consumption demands of Nigeria with improved technologies. International Rice Commission Newsletter, Vol. 49, FAO, Rome, pp. 23-41.

[6] Food and Agriculture Organization, 2000. Global network on integrated soil management for sustainable use of salt affected soils. Available at http//www.fao.org/ag/AGL/spush/Intro.html

[7] Singh, B. N., Fagade, S., Ukwungwu, M. N., Williams, C., Jagtap, S. S., Oladimeji, O., Efisue, A. and Okhidievbie, O., 1997. Rice growing environments and biophysical constraints in different agroecological zones of Nigeria. Met. J. 2 (1), pp. $35-44$

[8] Choi, H. C., Kwon, K. W., 1985. Evaluation of varietal differences and environmental variation for some characters related to source and sink in the rice plants. Korean Journal of Plant Breeding and Crop Science 30 (6), pp. 460-470.

[9] Zeng, L. and Shannon, M. C., 2003. Salinity Effects on Seedling Growth and Yield Components of Rice. Crop Science, 40, pp. 996-1003. 
[10] Efisue, A. A. and Igoma, E. A., (2019). Screening Rice (Oryza sativa. L.) In Salinity Gradient to Identify Performance During Vegetative Stage for Salinity Stressed Environment. Journal of Plant Science, 7 (6), pp. 144-150, Available through http://www.sciencepublishinggroup.com $/ \mathrm{j} / \mathrm{jps}$

[11] Yeo, A. R. Physiological criteria in screening and breeding. In Soil Mineral Stresses: Approaches to Crop Improvement; Yeo, A. R., Flowers, T. J., Eds.; Springer: Berlin, Germany, 1994; pp. 37-57.

[12] Efisue, A. A., Tongoona, P., Derera, J., and Ubi, B. E., 2009. Screening early generation progenies of interspecific rice genotypes for drought stress tolerance during vegetative phase. Journal of Crop Improvement, 23, pp. 174-193.

[13] Peng, Y. L., Gao, Z. W., Gao, Y., Liu, G. F., Sheng, L. X. and Wang, D. L. 2008. Eco-physiological characteristics of alfalfa seedlings in response to various mixed salt-alkaline stresses. Journal of Integrative Plant Biology 50, pp. 29-39. DOI: 10.1111/j.1744-7909.2007.00607.

[14] Fasahat, P., Abazar R., Javad M. R., and J. Derera, 2016. Principles and utilization of combining ability in plant breeding. Biometrics \& Biostatistics International Journal, 4 (1); $1-24$.

[15] International Rice Research Institute (IRRI). 1996. Standard evaluation system for rice. Los Baanos, Philippines: IRRI.

[16] Yoshida, S. 1981. Fundamentals of rice crop science. The International Rice Research Institute (IRRI). Los Banos, Laguna, Philippines. pp 269.

[17] SAS Institute Inc. 2003. SAS/STAT user's guide, version 9.1. Cary, NC: SAS Institute Inc.

[18] Pareek, A., Sopory, S. K., Bohnert, H. J. and Goindjee, 2010. Abiotic Stress Adaptation in Plant: Physiology, Molecular, and Genomic Foundation, Berlin: Springer.
[19] Emoghene, A., Hamadina, E. I., Efisue, A. A., 2015. Response of Hybrid Lowland Rice (Oryza sativa. L.) Cultiar FARO 44 to salinity incoastal plain sands of Niger Delta, Nigeria. Journal of Plant Science, 3 (2), pp. 106-110.

[20] Chandrasekaran. B, Annadurani. K, kavimant R. (2007). A textbook of rice science, Tamil Nadu agricultural university coimbatore. P- 46-47-667. ISBN: 81-7233-466-4.

[21] Efisue, A. A., Umunna, B. C. and Joseph, A. O., 2014. Effect of yield and yield components on yield potential of some lowland rice (Oryza satia. L.) in coastal region of southern Nigeria. Journal of Plant Breeding and Crop Science, 6 (9), pp. 119-127.

[22] Yoshida S (1983) Rice. In 'Potential productivity of field crops under different environments'. (Eds WH Smith, SJ Banta) pp. 103-127. (International Rice Research Institute Publishing: Los Bãnos). The Philippines.

[23] Ntanos, D. A., Koutroubas, S. D., 2002. Dry matter and N accumulation and translocation for indica andjaponica rice under Mediterrarian conditions. Field Crops., 74, pp. 93-101. Available at http://dx.dol.org/10.1016/S0378-4290(01)002039

[24] Halil Sürek and Necmi Beşer (2005). Response two-way selection for harvest index in two wheat (Triticum eastivum L.) crosses. Aust. Jour. Agric. Res. 28: 29-365.

[25] Olubukola G. A., Chinyere C. N., Richard O. A. and Julius O. F., 2017. Screening for yield related characters in some landrace accessions of Oryza sativa linn. In Nigeria. Journal of Plant Sciences., 12: 52-58.

[26] Mirza J. M., Ahmad Faiz and Abdul Majid. (1992). Correlation Study and Path Analysis of Plant Height, Yield and Yield Component. Sarhad J. Agric: 8 (6): 647-651. 